\title{
AVALIAÇÃO DA CORROSÃO LOCALIZADA EM AÇOS INOXIDÁVEIS AUSTENÍTICOS CONVENCIONAIS E DUPLEX, EM MEIOS CONTENDO CLORETO*
}

Andrew Thallisson de Souza ${ }^{1}$ Ramon Silveira Assis Barros² Luiz Cláudio Cândido ${ }^{3}$

\section{Resumo}

Os aços inoxidáveis ABNT da série 300 são ligas austeníticas $\mathrm{Fe}-\mathrm{C}(<0,08 \%)-\mathrm{Cr}(18$ a 20\%) - $\mathrm{Ni}(8$ a $10 \%)$ são muito aplicados, pois apresentam alta estampabilidade, alta soldabilidade, boa resistência à corrosão uniforme em vários meios corrosivos, no entanto, sofrem corrosão localizada (pites, corrosão sob tensão, fresta e corrosão intergranular). Os aços inoxidáveis da família UNS S32304, têm $23 \% \mathrm{Cr}$ e $4 \% \mathrm{Ni}$. Por terem teor de carbono inferior a $300 \mathrm{ppm}(0,03 \%$ em massa) são resistentes à corrosão intergranular, sofrem pites e corrosão sob tensão (CST). Devido ao alto teor de cromo, o aço UNS 32304 apresenta boa resistência à corrosão uniforme, sendo que na corrosão por pites o mesmo apresenta um comportamento melhor que os aços ABNT 304 (sem Mo) e ABNT 316 (com Mo), de acordo com o Número Equivalente de Resistência ao Pite (PREN). O PREN dos aços UNS 322304 é 26, e para os aços ABNT 304 e 316 são 18 e 25, respectivamente. Este trabalho caracterizou os diferentes aços inoxidáveis química, metalográfica e eletroquimicamente em meios contendo íons cloretos. A partir de ensaios de caracterização eletroquímica, por polarização potenciodinâmica, verificou-se que o aço ABNT 304 apresentou potencial de pite inferior aos aços ABNT 316 e o UNS 32304, em soluções aquosas contendo 3,5\% (massa) de $\mathrm{NaCl}$. Verificou-se que estes aços sofreram CST empregando-se ensaios de deformação (corpo de prova em U) e carga constante (corpo de prova de tração liso) nos eletrodos em soluções aquosas contendo $42 \%$ (massa) de $\mathrm{MgCl}_{2}$ na temperatura de aproximadamente $143^{\circ} \mathrm{C}$. Salienta-se que o comportamento em CST do aço ABNT 304 foi inferior aos demais. As amostras ensaiadas foram caracterizadas fratograficamente (macro e microfratograficamente - empregando-se microscopia eletrônica de varredura). Os corpos de prova que sofreram CST apresentaram facetas de clivagem e "marcas de rios", características da fratura frágil.

Palavras-chave: Aços inoxidáveis convencionais e duplex; Corrosão localizada; Ensaios de polarização e de corrosão sob tensão; Meios cloretados.

\section{CORROSION LOCATED IN STAINLESS AUSTENITIC CONVENTIONAL AND DUPLEX IN CONTAINING MEDIA CHLORIDES}

\section{Abstract}

Stainless steel AISI 300 series are austenitic alloys Fe-C (<0.08\%) - $\mathrm{Cr}(18-20 \%)-\mathrm{Ni}(8-10 \%)$ are the most applied worldwide, since they have high formability, high weldability, good resistance to uniform corrosion in various corrosive media, however, suffer localized corrosion (pitting, stress corrosion cracking (SCC), crevice and intergranular corrosion). The family of stainless steels UNS S32304, have $23 \% \mathrm{Cr}$ and $4 \% \mathrm{Ni}$. By having carbon content less than 300ppp (0.03\%) did not present intergranular corrosion, pitting and suffer SCC. Due to the high chromium content steel UNS 32304 shows good resistance to uniform corrosion, and the pitting corrosion it has a better behavior than the AISI 304 steel (no Mo) and AISI 316 (with Mo), according to Equivalent number of Resistance Pite (PREN). The PREN of steels UNS 322304 is 26, and the steel ABNT 304 and 316 are 18 and 25, respectively. This study characterized the different chemical stainless steel, metallographic and mechanically, besides the behavior of those in media containing chloride ions. From electrochemical characterization tests by potentiodynamic polarization curves, it was found that the AISI 304 steel showed pitting potential lower than AISI 316 steels UNS 32304 and in aqueous solutions containing $3.5 \%$ (weight) $\mathrm{NaCl}$. It was found that these steels suffer SCC employing strain testing (test piece $U$ ) and constant load (straight pull test specimen) in the electrodes in aqueous solutions containing $42 \%$ (mass) of $\mathrm{MgCl} 2$ at a temperature of approximately $143^{\circ} \mathrm{C}$. It is noted that the behavior of the steel AISI 304 SCC was lower than the others. The test samples were characterized microscopically employing scanning electron microscopy. The specimens that have undergone SCC showed cleavage facets and "marks of rivers", the brittle fracture characteristics.

Keywords: Conventional stainless steels and duplex; Localized corrosion; Polarization tests and stress corrosion cracking; Chlorinated media.

1 Aluno de Iniciação Científica do Curso de Eng. Metalúrgica (PROBIC) - DEMET, Escola de Minas, UFOP, Ouro Preto, MG, Brasil. and_ew10@hotmail.com.

2 Eng. Metal., M.Sc. - Escola de Minas, UFOP, MG, Brasil. ramonsilveiraassisbarros@yahoo.com.br.

3 Eng. Metal., M.Sc., D.Sc., Prof. do Dep. Eng. Metalúrgica e de Materiais, Escola de Minas, UFOP, REDEMAT, MG, Brasil. candido@em.ufop.br. 


\section{INTRODUÇÃO}

A corrosão é o fenômeno que promove a deterioração de um material, geralmente metálico, por ação química e/ou eletroquímica do meio ambiente associado ou não a esforços mecânicos. Os problemas de corrosão são frequentes e ocorrem nas mais variadas atividades, como por exemplo, nas indústrias química, petrolífera, petroquímica, naval, de construção civil, automobilística, nos meios de transporte aéreo, ferroviário, metroviário, marítimo, meios de telecomunicação, etc.

As ligas de aços resistentes à corrosão uniforme são aquelas que apresentam película passivante e são denominadas, inoxidáveis. Esses aços são ligas que contêm basicamente $\mathrm{Fe}-\mathrm{C}-\mathrm{Cr}$, sendo que o teor mínimo de cromo é 10,5\% (em massa). Dependendo de outros elementos de liga e teores de carbono são denominados aços inoxidáveis ferríticos, austeníticos e martensíticos. Além dos três tipos tradicionais de aços inoxidáveis existem duas outras famílias de aços que são os duplex (ferrítico/austenítico) e os endurecíveis por precipitação (de maior resistência mecânica).

Os aços inoxidáveis duplex UNS S32304 são bifásicos que têm em torno de $50 \%$ em fração volumétrica de ferrita e austenita. Por terem teores de carbono inferior a $300 p p m$ são imunes à corrosão intergranular, mas sofrem corrosão por pites e CST. Para estabilização da austenita adiciona-se nitrogênio que promove alta resistência mecânica na liga por ser elemento intersticial.

Este trabalho avaliou as características comportamentais de aços inoxidáveis empregando-se técnicas eletroquímicas (ensaios de polarização e ensaios de CST).

\section{MATERIAIS E MÉTODOS}

A partir de chapas de aço inoxidável, com $3 \mathrm{~mm}$ de espessura, foram confeccionados corpos de prova (CPs) para análises: química, metalográfica e eletroquímica. Para ensaios de CST utilizaram-se CPs, com 1,25mm de espessura, para deformação constante do eletrodo, do tipo em "U", e para os ensaios com carga constante, foram usados CPs lisos com a geometria de acordo com a Norma ASTM E468 (1990). Os cortes destes foram realizados por meio de técnica de água em alta pressão. As Figuras 2.1 e 2.2 ilustram a geometria e as dimensões destes CPs.

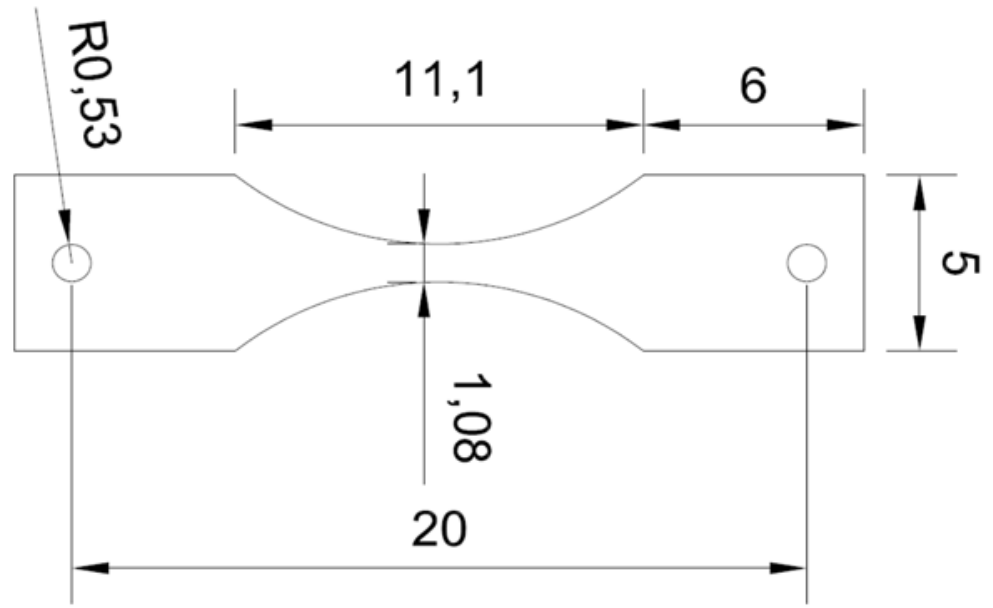

Figura 2.1 - Geometria e dimensões dos CPs para ensaios de CST com carga constante; unidade: $\mathrm{mm}$. 


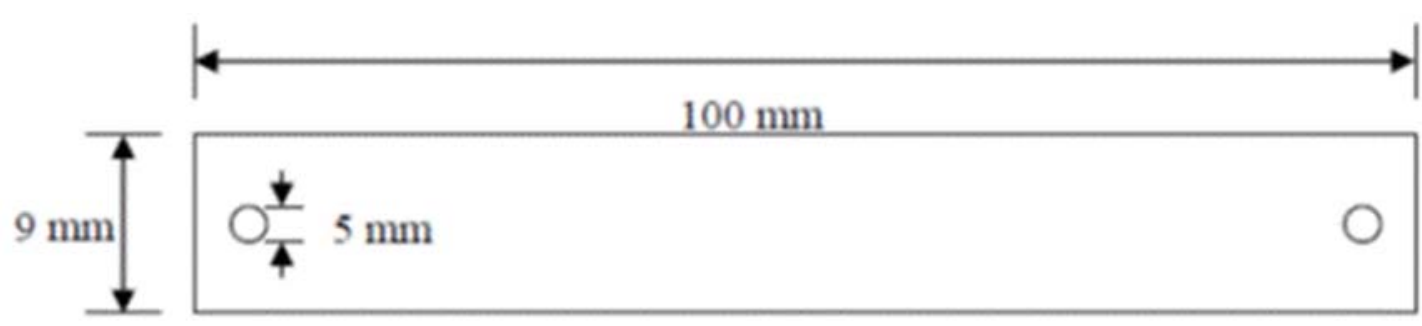

Figura 2.2 - Desenho esquemático do CP com espessura de 1,25mm, utilizado no ensaio de CST com deformação constante.

Para ensaios de polarização foi utilizado um potenciostato OMNIMETRIA Instrumentos Científicos Ltda, Modelo PG-05 e uma célula eletroquímica do tipo plana. Esta célula é composta por três eletrodos: eletrodo de trabalho (os materiais analisados: aços ABNT 304, ABNT 316 e UNS S32304), contra eletrodo de platina e um eletrodo de referência de calomelano saturado). As amostras foram lixadas até a lixa $n^{\circ}$ 600 , desengraxadas antes dos ensaios. A área exposta ao meio foi de $1 \mathrm{~cm}^{2}$. A taxa de varredura dos potenciais foi de $0,17 \mathrm{mV} / \mathrm{s}$. Foram realizados quatro ensaios para cada sistema liga/meio, adotando-se uma solução com 3,5\% (massa) de $\mathrm{NaCl}$, à temperatura ambiente.

Os CPs para ensaios de CST do aço UNS S32304 foram submetidos ao dobramento com o auxilio de um equipamento confeccionado para tal aplicação deixando-os com formato em "U", de acordo com a Norma ASTM G30/79. Depois de dobrados, os CPs foram fixados na região da união com parafusos e, estes, foram protegidos com resina epóxi e fita Teflon. Isso foi feito para se garantir que não ocorresse um relaxamento do regime elástico do material. Para o ensaio foram utilizadas soluções aquosas com $\mathrm{MgCl}_{2}$ $42 \%$ (massa) à $143^{\circ} \mathrm{C}$.

Para ensaios de CST com carga constante utilizou-se um equipamento ilustrado na Figura 2.3. O CP fica dentro de uma célula eletroquímica na presença de soluções cloretadas em ebulição. Este equipamento possui um relógio que registra o tempo de ensaio assim que o braço de alavanca atinge um sensor quando o CP rompe. Com o seu acionamento, o relógio registra o tempo de ensaio, e o sistema de aquecimento da célula é desligado, o que facilita e garante um acompanhamento mais preciso do ensaio.

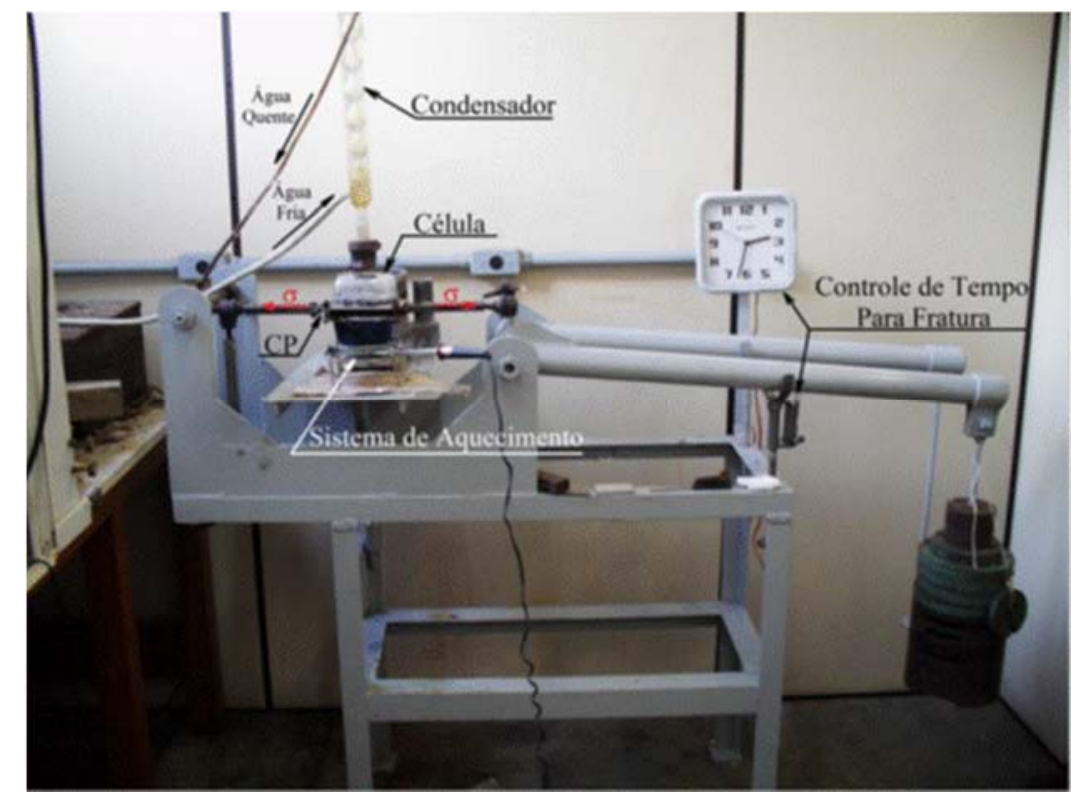

Figura 2.3 - Equipamento utilizado para ensaios de CST com carga constante. 


\section{RESULTADOS E DISCUSSÃO}

Levantaram-se curvas de polarização potenciodinâmica dos aços em soluções aquosas contendo 3,5\% (massa) $\mathrm{NaCl}$ para obtenção de parâmetros eletroquímicos característicos, na temperatura ambiente. Empregaram-se recursos on-line composto por um computador e um potenciostato/galvanostato (PAR, modelo $273 \mathrm{~A}$ ) interligado por uma interface padrão IEEE - 488 (SoftCorr III), com taxa de varredura de $0,17 \mathrm{mV} / \mathrm{s}$. A célula eletroquímica utilizada foi de três eletrodos, com contraeletrodo de platina, o eletrodo de referência de calomelano saturado e o eletrodo de trabalho.

Inicialmente, estabilizou-se o potencial de corrosão por 3600 segundos. Com isso, obtêm-se as curvas potencial $(E)$ versus tempo (t). Posteriormente, é feita a varredura na aplicação de potenciais $(250 \mathrm{mV}$ abaixo do potencial de corrosão estabilizado, até $1600 \mathrm{mV}$ ). A Figura 3.1 apresenta as curvas de polarização potenciodinâmica para os aços ABNT 304, ABNT 316 e UNS S32304. De acordo com as curvas de polarização, o aço ABNT 304 apresentou potencial de pite de $180 \mathrm{mV}$ ECS, O ABNT $316400 \mathrm{mV}_{\mathrm{ECS}}$ e o aço inoxidável duplex UNS S32304 $900 \mathrm{mV}$ ECS. Nota-se na curva do aço UNS S32304 certa instabilidade na região de desenvolvimento de pites, em potenciais em torno de $800 \mathrm{mV}$ ECS.

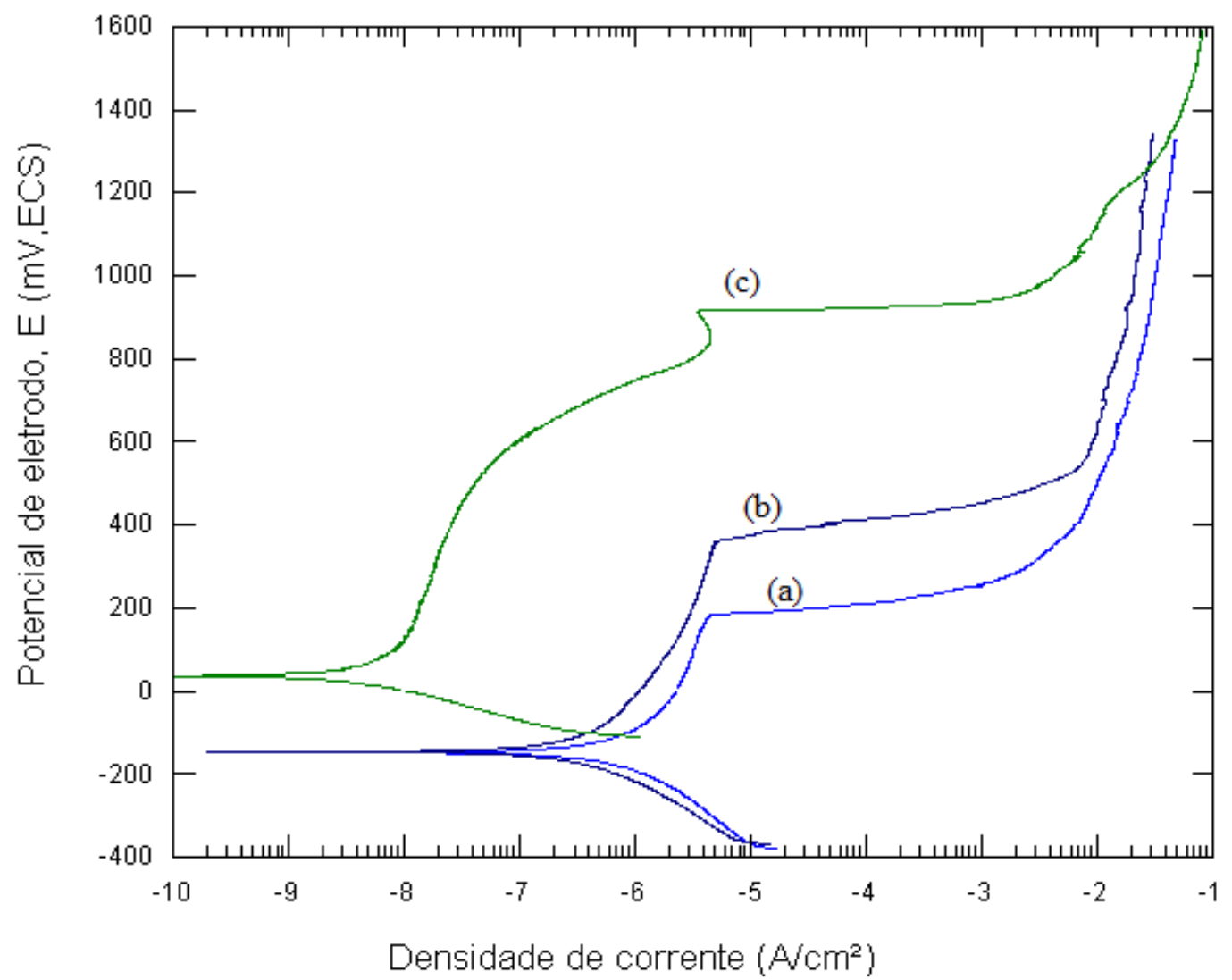

Figura 3.1 - Curva de polarização potenciodinâmica do aços (a) ABNT 304, (b) ABNT 316 e (c) UNS S32304; solução 3,5\%, em massa, de $\mathrm{NaCl}$ à temperatura ambiente; $0,17 \mathrm{mV} / \mathrm{s}$.

BRAGA (2011) estudando o comportamento do aço ABNT 304 em solução aquosa de $\mathrm{NaCl}$ observou que o valor do potencial de pite foi de 200mVECS. Já BARROS (2015) nessas mesmas condições obteve o valor de 400 mVECS para o aço UNS S32304. Ressalta-se que o acabamento superficial dos CPs, nos ensaios de polarização, tem grande influência nos valores de potenciais de pite dos materais. 
Devido ao alto teor de cromo, o aço UNS S32304 apresenta boa resistência à corrosão uniforme, sendo que na corrosão por pites o mesmo apresenta um comportamento melhor que os aços ABNT 304 (sem Mo) e ABNT 316 (com Mo) de acordo com o coeficiente de resistência ao desenvolvimento de pite (PREN - Pitting Resistence Equivalent Number). O PREN pode ser calculado pela fórmula : PREN = $\% \mathrm{Cr}+3,3 \mathrm{x} \% \mathrm{Mo}+16 \mathrm{x} \% \mathrm{~N}$. O PREN do aço UNS S32304 é 26 , e para os aços ABNT 304 e 316 são 18 e 25, respectivamente.

Após preparação e dobramento de CPs para os ensaios de CST com deformação constante do eletrodo (CP) estes foram desengraxados e colocados em uma célula, com aquecimento por resistência elétrica, e emprego de um condensador. Depois de setenta e duas horas, o ensaio foi encerrado ao verificar-se o surgimento de trincas nos mesmos. A Figura 3.2 apresenta um CP trincado por CST.

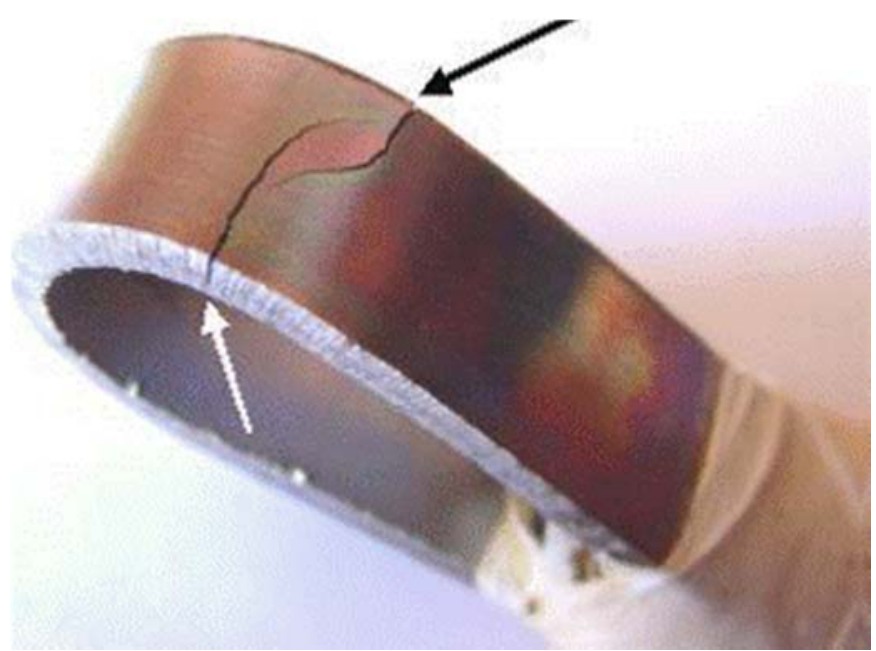

Figura 3.2 - Macrofractografia de um CPs ensaidos por CST com deformação constante do sistema: aço UNS $\mathrm{S} 32304 / 42 \% \mathrm{MgCl}_{2}\left(143^{\circ} \mathrm{C}\right)$.

No ensaio de CST com carga constante do eletrodo ensaiou-se o aço UNS S32304 também em um meio contendo $42 \%$ em massa de $\mathrm{MgCl}_{2}\left(143^{\circ} \mathrm{C}\right)$. A carga aplicada foi de aproximadamente $43 \mathrm{kgf}$, correspondendo a $53 \%$ do limite de escoamento do aço ( $\sigma_{e}$ = 599MPa) que é valor fornecido pela Cia. APERAM South America. Verificou-se que a solução aquosa empregada comprometeu consideravelmente a integridade do material na tensão inferior ao limite de escoamento do mesmo. O aço rompeu após 22 horas de ensaio, nesse nível tensão aplicado. Assim, verificou-se que a combinação carga e meio corrosivo são fundamentais para a ocorrência do fenômeno de CST.

BARROS (2015) estudando o comportamento em CST do aço UNS 532304 em soluções de $\mathrm{MgCl}_{2}$ em ebulição, para valores de $70 \%, 50 \%, 30 \%, 20 \%$ e $15 \%$ do limite de escamento do aço, também observou que a temperatura do meio cloretado reduziu o tempo de ruptura do aço. A combinação de um material suscetível, um meio corrosivo específico e tensão fazem com que o material tenha um comportamento completamente distinto do esperado, mesmo em tensões bem inferiores ao seu limite de escoamento.

Outra evidência do fenômeno pode ser observada na Figura 3.3 que mostra a microfractografia de um CP obtida empregando-se análise por MEV. Como o fenômeno de CST promove a fragilização do material (mecanismo de dissolução anódica na ponta da trinca), nota-se a presença de marcas de "rio" e facetas de clivagem, características da fratura frágil. O arrancamento final ocorre, de maneira catastrófica, por ruptura mecânica, de maneira dúctil, indicando a presença de dimples, características dessa fratura. De acordo com CÂNDIDO (1996), o trincamento por CST ocorre preferencialmente na ferrita 


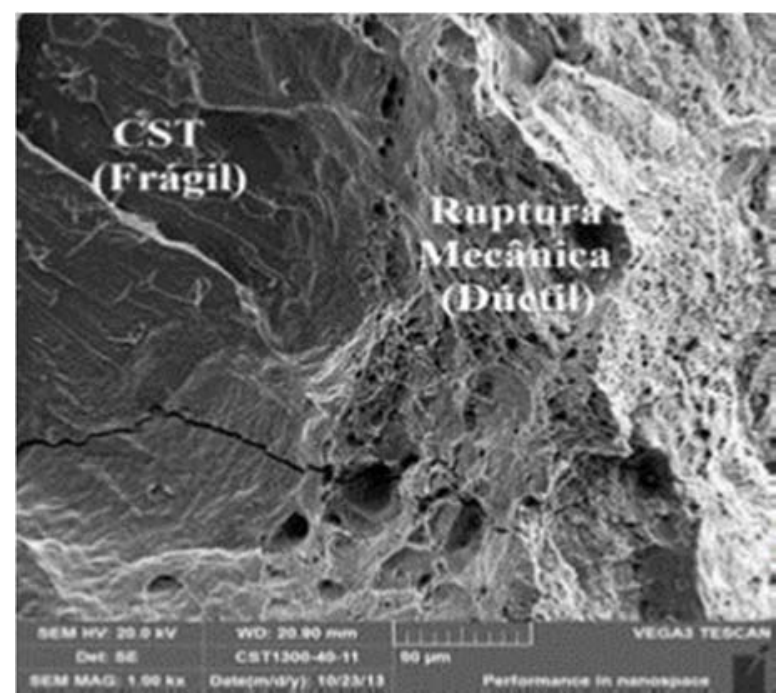

Figura 3.3 - Microfractografia de um CP ensaiado por CST com carga constante para o sistema UNS S32304/42\% $\mathrm{MgCl}_{2}\left(143^{\circ} \mathrm{C}\right) ; 1000 X ; \mathrm{MEV}$. Região frágil (CST) e dúctil (Ruptura Mecânica).

\section{CONCLUSÕES}

- A partir de ensaios de caracterização eletroquímica, por polarização potenciodinâmica verificou-se que o aço ABNT 304 apresentou potencial de pite inferior aos aços ABNT 316 e o UNS S32304, em soluções aquosas contendo $3,5 \%$ (massa) de $\mathrm{NaCl}$.

- Verificou-se que o aço UNS S32304 sofreu CST empregando-se ensaios de deformação e carga constante em soluções aquosas contendo $42 \%$ (massa) de $\mathrm{MgCl}_{2}$ na temperatura de aproximadamente $143^{\circ} \mathrm{C}$.

- Os CPs ensaiados em CST apresentaram fratura frágil com presença de facetas de clivagem.

\section{Agradecimentos}

Os autores agradecem à FAPEMIG pela concessão da bolsa de Iniciação Científica, a Pró- Reitoria de Pesquisa e Pós-Graduação da UFOP e a Empresa APERAM South America pela doação das chapas metálicas.

\section{REFERÊNCIAS}

1 AMERICAN SOCIETY FOR TESTING AND MATERIALS. Standard practice for presentation constant amplitude fatigue test results for metalic materials, designation: E468 - 90. West Conshohocken, Pennsylvania, USA, 2003.

2 AMERICAN SOCIETY FOR TESTING AND MATERIALS. Standard recommended practice for making and using U-Bend stress corrosion test specimens, designation: G30 - 79. West Conshohocken, Pennsylvania, USA, 2003

3 BARROS, R. S. A. Suscetibilidade à corrosão sob tensão em aços inoxidáveis duplex UNS S32304 em meios contendo cloretos. Dissertação de Mestrado, REDEMATUFOP, 2015.

4 BRAGA, T. M. T. Efeito de entalhe e de meios cloretados na corrosão sob tensão de um aço inoxidável ABNT 304. Dissertação de Mestrado, REDEMAT-UFOP, 2011.

5 CÂNDIDO L. C. Corrosão Sob Tensão de Aços Inoxidáveis Duplex em Soluções Aquosas Contendo Cloretos na Temperatura de Ebulição, através de Diferentes Técnicas Experimentais. Tese de Doutorado - UFMG, 1996. 
6 JONES, R. H., RICKER, R.E. Mechanisms of Stress-Corrosion Cracking. In: JONES, R. $\mathrm{H}$. Stress-Corrosion Cracking: Materials Performance and Evaluation. Ohio. ASM International, 1993.

7 WOLYNEC, S. Técnicas Eletroquímicas em Corrosão. Editora EDUSP, 2002. 